\title{
The Jurisprudence Analysis of Legislative Control of New Type Tobacco Products in China
}

\author{
Lina She ${ }^{1, *}$, Shunliang Tang ${ }^{2}$ and Quan Liang ${ }^{3}$ \\ ${ }^{1}$ Science and Technology Department, Kunming University, Kunming, Yunnan, China \\ ${ }^{2}$ L. H. L Law Firm, Intellectual Property Department, Kunming, 650231, China \\ ${ }^{3}$ Agricultural College, Yunnan Agricultural University, Kunming, 650100, China \\ *Corresponding author. Lina She. Email: 51422598@qq.com
}

\begin{abstract}
In order to explore the legislative control of new tobacco products under China's tobacco monopoly system, this work focused and had a discussion on four aspects based on the Framework Convention on Tobacco Control (FCTC), the domestic law, and market environment: legislative value orientation, legislative level, purpose and object of tobacco monopoly law, and factors to be considered in tobacco monopoly law. Conclusion: The country needs to speed up the formulation of industry technical standard system and normative documents, and then include new tobacco products into monopoly management targets. Besides, whether it is technology research and development or control policy research, it ought to follow the rules of the market and consider the product quality and the formulation of regulations on all aspects of the foreign brand from the perspective of legal risk's prevention and control.
\end{abstract}

Keywords: New type tobacco, Control, Jurisprudence analysis

\section{INTRODUCTION}

To make a legislative analysis of a new thing, we must first clarify its object and concept, and define the technical characteristics of the new technology or new product before conducting an in-depth jurisprudence analysis. If the objects of legislative supervision cannot be classified and defined, the boundaries of law enforcement cannot be determined as well. For example, in order to accurately define e-waste, it is necessary to get started by analyzing its essential characteristics. The essence of e-waste is waste, and the essential feature of waste lies in its disusability. The waste directive which was issued by EU closely tied to this feature when it gave the definition of waste[1].

Among the various definitions of new tobacco products, the definition of the FCTC text has legal significance and generality, which includes: electronic nicotine delivery system. It transmits aerosol by heating a solution for users to inhale and can divide into 2 types, nicotine and non-containing nicotine; heating non-burning cigarettes. The smoking material is usually a solid material. Through electric heating or other heating methods, the smoking material emits smoke for users to inhale without burning, strictly speaking, it also belongs to a kind of electronic nicotine delivery system; smokeless tobacco. It represents for the tobacco which is consumed through the mouth or nose. Buccal products include tobacco tablets, tobacco gum, and tobacco water. Moreover, there are two types of snuff, dry and wet, and users inhale a small amount of fine smoke powder mixed with spices through the nose [2].
According to the official definition of the framework convention, and on the basis of reference to foreign regulatory government control, the next step is to conduct jurisprudence analysis based on the domestic legislative environment and monopoly system.

\section{THE OVERVIEW OF THE DEVELOPMENT AND LEGISLATION OF NEW TYPE TOBACCO PRODUCTS IN CHINA AND AT ABROAD}

According to data from the World Tobacco Report, in 2019, the global sales of e-cigarettes (excluding heat and non-combustion) exceeded 231.1 billion yuan (US\$33 billion), which is an increase of $106 \%$ year-on-year compared to 2018 . China contributed 11 billion yuan to the global market. Compared with the performance of 4.55 billion yuan in 2018, it has increased by $175 \%$ year-on-year in 2019[3]. On the basis of the statistics in 2017, 52 countries around the world have legislated to regulate electronic nicotine delivery systems[4-5].

China is already a major producer of new type tobacco products, and domestic consumption is gradually increasing. This undoubtedly involves public health and requires an orderly competitive and regulated market. Nowadays, reports on the harm, quality, and market chaos of new tobacco products continue to appear, which constitute the economic reason and basis for government intervention[6]. 


\section{THE QUESTION OF WHETHER LEGISLATION OF PROHIBITION IS ADVISABLE}

In the current situation of tobacco control, anti-smoking organizations, public health departments, research institutions, and scholars will all put forward reasons for prohibition from various angles, citing the practices of foreign countries that are fully and partially prohibited to thereby affect the legislative tendency of regulatory agencies. However, the technical boundaries of new tobacco products have not yet been clarified, and technical demonstrations are ongoing, and the prohibition lacks scientific evidence support.

In addition, in accordance with the general theory of legislation, prohibitive norms that apply to the entire country need to be stipulated by the National People's Congress or the Standing Committee of the law, or within the scope of the law, the next-level legislature should make supplementary legislation to enforce the law. According to Article 8 of Legislation Law of the People's Republic of China, the matters that must be enacted mainly involve national sovereignty, basic economy and property, and civil rights and obligations. Nevertheless, new type tobacco products have not risen to the level of national legislation prohibition. Consequently, legislatures at levels below the
State Council have no legal authority to prohibit the existing rights of subjects related to new tobacco products. Meanwhile, it is technically difficult to prove that new tobacco products are more harmful than traditional cigarettes. Therefore, it is not advisable to force legislation to prohibit it, and it does not conform to the current market economy legislation environment as well.

\section{THE QUESTION OF LEGISLATIVE VALUE ORIENTATION}

The health institutions of some countries in the world only use technical regulations to limit the components and content of substances that affect public health in products. At present, the composition of cigarettes, especially whether they contain nicotine, is a key factor that determines the degree of supervision by governments of various countries. Legislation on e-cigarettes in various countries can be divided into five categories. The degree of supervisions is classified from mild to severe: general consumer product supervision, unified tobacco product supervision, medicinal product supervision, sales prohibition and sales and use prohibition[7].

Table 1 Legal supervision of electronic cigarettes in various countries

\begin{tabular}{|l|l|}
\hline \multicolumn{1}{|c|}{ The classification of supervision measures } & \multicolumn{1}{c|}{ Countries and regions } \\
\hline $\begin{array}{l}\text { No policies related to e-cigarettes (including nicotine) have been } \\
\text { released. E-Cigarettes (excluding nicotine) are regarded as ordinary } \\
\text { consumer goods }\end{array}$ & Russia, China, Pakistan, Ukraine \\
\hline Regard electronic cigarettes (including nicotine) as tobacco products & $\begin{array}{l}\text { Britain, Germany, Italy, United States, } \\
\text { Poland, France, Ireland, Spain, Croatia, } \\
\text { Netherlands, } \\
\text { Slovenia, Israel, Czech Republic, Bulgaria, } \\
\text { Finland, Latvia, Costa Rica, } \\
\text { Korea, Peru, Serbia, Morocco, Romania, } \\
\text { Hungary, Slovakia, Portugal, Austria }\end{array}$ \\
\hline List electronic cigarettes (including nicotine) as medicinal products & $\begin{array}{l}\text { Denmark, Canada, Sweden, Philippines, } \\
\text { Belgium, South Africa, Chile, New Zealand }\end{array}$ \\
\hline & $\begin{array}{l}\text { Egypt, Australia, Mexico, Honduras, Costa } \\
\text { Rica, Panama, Colombia, Brazil, } \\
\text { Argentina, Uruguay, Norway, Switzerland, } \\
\text { Turkey, Saudi Arabia, Oman, Thailand, }\end{array}$ \\
Prohibit the sale of e-cigarettes (including nicotine) & $\begin{array}{l}\text { Uganda, } \\
\text { Brunei, Qatar, UAE, Venezuela, Seychelles }\end{array}$ \\
\hline Prohibit the sale and use of e-cigarettes (including nicotine) & Indonesia, Malaysia, Colombia, Singapore \\
\hline
\end{tabular}

Accordingly, it can be considered that its value orientation is to maintain market order and consumer health, and the state of ruled management ought to be resolved first, and the new type tobacco products market may develop soundly.

\section{THE QUESTION OF LEGISLATIVE LEVEL}

Only established in basic legal principles, respecting the basic rules of law application, and comprehensively 
adopting literal and logical technical measures, can it be possible to conduct a comprehensive analysis of the meaning contained in a clause[8]. Expansion of the interpretation of the monopoly object is essentially an expansion of property rights. The interpretation agency will maintain a cautious attitude and may require more demonstrations from the industry authorities.

On the other hand, the supervision of new type tobacco products may involve issues such as hygiene, quality, industry and commerce, taxation, tobacco, etc. From the perspective of ministries and commissions, it is advisable to first formulate management methods at the regulations level methods to solve the problem of whether there is a system of management, and then continue to improve according to the actual operating conditions thus to upgrade from the legislative level.

\section{THE PURPOSE AND OBJECT OF TOBACCO MONOPOLY LAW}

After the tobacco industry proposed the development strategy of new tobacco products, relevant experts in the industry believed that the management of new tobacco products as monopoly products is the most feasible solution. Mainly since new tobacco products (especially e-cigarettes) are most similar to traditional cigarettes, especially in terms of appearance and hazards, social acceptance is high, and the mature regulatory framework of tobacco can be directly employed, which can promote the rapid and orderly development of new tobacco products, especially electronic cigarettes. Moreover, irregularities related to issues such as advertising, product quality, consumer health protection, taxation, etc., can be better resolved if they are included in the track of tobacco control [9]. In this regard, the legitimacy of inclusion is examined from the following two points.

\subsection{The legislative purposes of the tobacco monopoly law}

In order to implement tobacco monopoly management, organize the production and operation of tobacco monopoly products in a planned way, improve the quality of tobacco products, protect the interests of consumers, and ensure the state's fiscal revenue, this law is formulated. This is the legislative purpose of the tobacco monopoly law, that is, to solve the order and quality of tobacco business, to ensure the interests of consumers and the state's taxation. Its legislation is "forbidden by taxation", through monopoly to ensure its national planning, authorize state operations, and increase state taxation.

\subsection{The supervision targets of the tobacco monopoly law}

Tobacco monopoly products refer to cigarettes, cigars, shredded tobacco; redry tobacco leaves, tobacco leaves, cigarette paper, filter rods, tobacco tow, and special tobacco machinery. Among them, cigarettes, cigars, shredded tobacco, and redry-cured tobacco are collectively referred to as tobacco products. This article accurately defines tobacco monopoly and tobacco products. The necessary technical feature is the characteristic substance of tobacco. Whether it is management or technology, the raw material of tobacco leaf is the starting point of manufacturing and the end of sales, while the process is tobacco machinery. On the other side, in order to expand the targets of the tobacco monopoly law, apart from going through the statutory legislative procedures, interpretations that are made on the targets of expansion are also necessary. Consequently, when investigating the monopoly of new tobacco products, the concept of tobacco needs to be added for subdivision. The law does not allow non-tobacco monopoly objects to be included. Therefore, it is necessary to solve the conceptual problems of smoking articles, tobacco, tobacco leaves, tobacco extracts, cigarette reduction, and e-liquid involved in new tobacco products to thereby clarify the objects of legislative control.

\section{THE FACTORS TO BE CONSIDERED FOR INCLUSION IN TOBACCO MONOPOLY}

\subsection{Whether it can solve the overall regulatory issue or not}

At present, the inclusion of monopoly cannot solve the problem of comprehensive and orderly supervision that the society expects, and the tobacco industry can only manage the production and sales of new tobacco products that involve "tobacco" within a certain range. From this perspective, the tobacco industry's scope of inclusion is still within the scope of the existing tobacco monopoly law, and there is no need to amend the law. To a certain extent, the issue of production and sales of tobacco companies can be solved through the issuance of regulatory documents for the implementation of new tobacco products using tobacco as raw materials by the tobacco administrative department.

\subsection{The question of industry level supporting regulations}

The supervision of new type tobacco products is mainly divided into the supervision of tobacco use in the manufacturing process and the supervision of end products such as smoking sets, tobacco leaves, tobacco extracts, and e-liquid in the market circulation link. There is a question about how to incorporate new tobacco products into monopoly management, how to solve the 
problem of non-tobacco enterprise supervision, and whether to include existing e-cigarette factories under the supervision of the tobacco industry. This is a kind of misunderstanding. The competent tobacco administration department has no legal responsibility to supervise such market entities, since electronic cigarettes that do not involve the use of tobacco do not belong to the scope of monopoly law management. For e-cigarette products that do not need to be included in monopoly management, there are no legal obstacles for cigarette companies to operate. As long as they are not products that are franchised, restricted or prohibited by law, tobacco enterprises can operate after completing changes in accordance with the company's business scope change registration rules. Accordingly, it is important to consider how to formulate industry regulatory rules, determine the relationship with non-tobacco companies and the boundaries of law enforcement.

\subsection{How to speed up the technical system which can support legislation}

At present, the supervision of new type tobacco in foreign countries is mainly based on technical regulations. The practice of some developed countries or regions with high levels of food safety legislation and supervision shows that the transformation and priority application of international food safety standards must be highlighted[10]. The design of a series of policies including new tobacco product declaration, market testing, circulation requires to be built on a certain technical basis, and lacks the support of relevant technical standards. At present, there are only the General Technical Requirements for Electronic Cigarette Liquid Products issued by the Shenzhen Entry-Exit Inspection and Quarantine Bureau. However, it does not belong to a national standard[11]. Relevant authorities lack a basis for review. For instance, a series of issues such as how to set limited ingredients need to be resolved in advanced technology.

\section{CONCLUSION}

First, it is necessary to organize and speed up the control of legal level, and then formulate industry technical standard systems and regulatory normative documents to solve the problem of which physical new tobacco products should be included in the monopoly management: tobacco leaves, tobacco shreds, or tobacco leaf extracts. The second is to deal with the problem of new tobacco monopoly law enforcement, and then gradually promote higher-level legislation, which is in line with the usual practice of bottom-up legislation management of China.

Second, the development trend of new tobacco products is more market-oriented than traditional cigarettes. Whether it is technology research and improvement or control policies research, it is important to follow the rules of market and grasp development trends.
Third, it is indispensable to consider the formulation of regulatory rules from the perspective of legal risk prevention and control. Once the industry enters the market, it requires to use rules to ensure orderly competition. In addition, the product itself also involves a series of legal issues, including product quality, foreign brand imports, advertising and packaging, tobacco control, intellectual property rights, etc. The research and formulation of rules must take into account the legal risk handling mechanism caused by market access.

\section{ACKNOWLEDGMENT}

This work was financially supported by Talent Introduction Research Project of Kunming University (YJL20190010).

\section{REFERENCES}

[1] Chen Chen. Exploration of the Legal Definition of E-waste-Enlightenment from EU Legislation, Journal of Global Economics [J]. 2006(9): pp. 52-53.

[2] World Health Organization. Framework Convention on Tobacco Control FCTC [EB/OL],https://baike.sogou.com/v1692459.htm?from Title $=\%$ E7\%83\%9F\%E8\%8D\%89\%E6\%8E\%A7\% Е5\%88\%B6\%Е6\%A1\%86\%Е6\%9E\%B6\%Е5\%85\% AC\%Е7\%BA\%A6, 2003-5-21.

[3] Caixin.com. China's e-cigarette sales surged $175 \%$ to 11 billion yuan in 2019 [EB/OL]. http://www.caixin.com/2019-12-18/101495576.html, 2019-12-18

[4] Xia Yinghua. The Impact of Electronic Cigarettes on Human Health and the Progress of Its Control[J]. Chinese Public Health, 2018: pp.1-3.

[5] Eric Feldman. My Humble Opinion on China's Electronic Cigarette Supervision[J]. Journal of Chinese Tobacco, 2015(277): pp.76-85.

[6] Yao Zhigang, Mao Zhengzhong. The Economic Rationality of Government Intervention in the Tobacco Market, Chinese Health Service Management[J]. No. 5, 2002.

[7] Li Lei, Zhou Ningbo, Qu Xianghui. Market Development and Legal Supervision of New Tobacco Products[J]. Chinese Tobacco Journal, 2018, 24(02): pp. 100-110.

[8] Hu Yuhong. Respect for the Law: The First Principle of Judicial Interpretation, Journal of East 
China University of Political Science and Law[J].2010, Issue 1: pp.104-106.

[9] Li Baojiang. Global E-cigarette Market Development, Major Disputes and Government Regulation, Chinese

Tobacco Journal[J]. August, 2014, Volume 20, Issue 4: pp. 101-106.
[10] Tu Yongqian, Zhang Qing. The Status of International Food Safety Standards in Chinese Food Safety Legislation and Its Legislative Improvement, Social Science Research[J]. 2013 Vol. 3: pp. 77-81.

[11] Wang Yao. The Development Status of Electronic Cigarettes and Future Research Ideas[J]. China Science and Technology Information, 2017(09): pp. 49-50. 